\title{
Developmental Stages of Learning Psychotherapy
}

Duncan B. Clark, PhD, MD

Stanford University Medical Center

Follow this and additional works at: https://jdc.jefferson.edu/jeffjpsychiatry

Part of the Psychiatry Commons

Let us know how access to this document benefits you

\section{Recommended Citation}

Clark, PhD, MD, Duncan B. (1987) "Developmental Stages of Learning Psychotherapy," Jefferson Journal of Psychiatry. Vol. 5 : Iss. 2 , Article 11.

DOI: https://doi.org/10.29046/JJP.005.2.008

Available at: https://jdc.jefferson.edu/jeffjpsychiatry/vol5/iss2/11

This Article is brought to you for free and open access by the Jefferson Digital Commons. The Jefferson Digital Commons is a service of Thomas Jefferson University's Center for Teaching and Learning (CTL). The Commons is a showcase for Jefferson books and journals, peer-reviewed scholarly publications, unique historical collections from the University archives, and teaching tools. The Jefferson Digital Commons allows researchers and interested readers anywhere in the world to learn about and keep up to date with Jefferson scholarship. This article has been accepted for inclusion in Jefferson Journal of Psychiatry by an authorized administrator of the Jefferson Digital Commons. For more information, please contact: JeffersonDigitalCommons@jefferson.edu. 


\title{
Developmental Stages of Learning Psychotherapy
}

\author{
Duncan B. Clark, Ph.D., M.D.
}

The contradictory philosophies of the major schools of psychotherapy present a dizzying array of alternative approaches for the psychiatry resident. The academic efforts that have been made to synthesize differing approaches to psychotherapy have not met with widespread acceptance. Part of the reason why such a synthesis has been slow in coming may be found in the stages of development the practitioner goes through in learning psychotherapy. The concepts of developmental psychology discussed by Chandler (7) in describing the adolescent's confrontation with relativism and 'epistemological loneliness' can help us understand some of the cognitive problems faced by the psychiatry resident. Unfortunately, most residents choose one particular approach to psychotherapy during training, and adhere to that method throughout their professional careers. The philosophical approach of "pluralism" describes a less limiting solution to the problem of differing world views, and may provide a model for a more integrated approach to psychotherapy.

\section{INTRODUCTION}

Despite the apparent uniqueness of each psychiatrist's development as a psychotherapist, there are common themes that structure the neophyte's interest in learning theory and technique, influence choice of theoretical perspective, and militate against the synthesis of the major schools of psychotherapy. The initial years of training are often confusing and discouraging. The contradictory philosophies of the major schools of psychotherapy, i.e. the psychoanalytic, behavioristic, and humanistic schools, as well as the sometimes competing strategies of family, group and pharmacologic therapies, present a dizzying array of alternative approaches. The debate with regard to the education of residents has recently become more fundamental, with psychiatric residents and faculty posing the question, "Should psychotherapy be taught to psychiatric residents?" (1). To compound the problem for the resident, supervisors often adhere vehemently to a particular school of thought and contradict each other with maddening consistency and confidence.

Dr. Clark is a third year resident at Stanford University Medical Center. He would like to acknowledge the support of NIMH grant \#MH16744 during the writing of this article. 
Despite the fact that most residents initially express an interest in the use of a variety of approaches, most choose one particular school of thought with its attendant methods by the end of training. Nearly four decades since the synthesis attempted by Dollard and Miller's Personality and Psychotherapy (2) have produced only a handful of similar works, and no major school of thought for psychotherapy. Efforts in this direction have taken two forms, the single school "expansionist" model, e.g. Meichenbaum (3), and the cross school "integrationist" model, e.g. Wachtel (4). Despite predictions that a crisis is approaching which may result in techniques from diverse theories being combined into a common practice (5), there has in fact been little movement in that direction.

The reason often cited for the lack of progress in solving this problem is the inherent incompatibility of the philosophical bases and methodological commitments of the major schools (6). This explanation begs the question. Like the six blind men with the elephant in the famous parable, we are all attempting to explicate the nature of man and in our more limited endeavor, to develop a single psychological theory from which logical choices can be made concerning the best psychotherapeutic approach to a particular patient.

The importance of at least a truce between the various factions is critical to our healthy survival as a profession. Given the logical appeal and current necessity of a comprehensive approach, one wonders what has kept us apart besides the usual philosophical differences which have been argued to exhaustion. Part of the answer may be found in the stages of development the practitioner goes through in learning psychotherapy.

\section{DEVELOPMENTAL STAGES}

The concepts discussed by Chandler (7) in describing the adolescent's confrontation with relativism and "epistemological loneliness" can help us understand some of the cognitive problems that face the psychiatry resident. With the mastering of formal operational thought in early adolescence, the realization of relativism is accompanied by a sense of isolation and estrangement. There is a gradual awareness of what Sartre (8) has called a "plurality of solitudes" which results in an uneasiness with a lack of personal identity, a "vertigo of relativity." One can analogously describe the initial confusion of the neophyte psychotherapist. The resident early becomes painfully aware of the diversity, complexity, and, despite glaring contradictions, reasonableness, of the major schools of psychotherapy. Without a logical place to get started, one initially learns bits and pieces of theories and techniques, unable to completely understand or practice any method, sharing little but confusion with peers. What better description of "epistemological loneliness"!

In the adolescent, a variety of regressive solutions are used to come to terms with this dilemma. One means is to search out a group of peers and develop a "negotiated consensus." By binding together into a univocal social collective, with an attitude of "cognitive conceit," adolescents seek to ward off the sense of estrangement which accompanies their realization of relativity. Any 
chink in the unified ideological front is expeditiously eliminated, lest the isolation of being different reassert itself. The analogous solution to the dilemma of the beginning psychotherapist is the development of a negotiated consensus through selective collegial relationships. The most obvious manifestations of the ideological front in psychiatry are the laboratory group at the university and membership organizations built around particular schools of thought, which may include group practices. The less experienced the practitioner, the more dogmatic the approach, since the neophyte's identity is poorly developed and easily threatened.

Efforts to find a negotiated consensus do not always take the form of group behavior and may be manifested in the search for intimacy found in the plurality of two. A young adolescent's relationship with a parent may serve such a function, both for parent and child, when the child is viewed for his or her special status as a "chip off the old block." Similarly, the supervisor-resident relationship may take on a "you and me against the world" posture which bolsters the student's identity with a more mature model than the peer group. The supervisor likewise benefits, albeit in a regressive way, from a negotiated consensus wherein the negotiation is minimal. Such a position is not without its hazards, however, in that the resident eventually sees the limitations of the approach advocated and, in reaction to the previous aggrandizement, a devaluation may take place that is disheartening for both.

A companion method the adolescent uses to ward off the threat imposed by individuality is to blur out of focus the distinctness which characterizes outgroup persons and dispense with them en masse. A similar strategy is used in the bickering between the advocates of different schools of psychotherapy, who proclaim all the theories and techniques of other major schools of thought useless.

Methods the adolescent uses to construct a negotiated consensus do not necessarily involve available sources of social support. A sense of ideological companionship may be sought by opting into some prepackaged world view, which may take the form of religious conversion or the adoption of a secular life philosophy. Differences of opinion are considered to be correctable errors in human judgement which serve to becloud the real truth. Several advocates of schools of thought in personality theory and psychotherapy have sought to elevate their ideas to the status of world views by making broad comments about society, such as B.F. Skinner in Beyond Freedom and Dignity (9) and Sigmund Freud in Civilization and Its Discontents (10). Such theories do have appeal as world views, particularly to the relatively young and idealistic resident who may at once be struggling with the trials and tribulations of young adulthood and learning psychotherapy.

All these regressive solutions attempt to deal with the multiplicity of perspectives by denying their legitimacy out of hand. These solutions inhibit the cross-fertilization of ideas that is necessary for the study of psychotherapy to go forward. Unfortunately, by the time most psychiatrists have completed their 
training, they are often committed to such a relatively regressive solution. When the more experienced psychotherapist finally does realize the limitations of the single school perspective, he or she is usually deeply committed personally and professionally to a single school approach. One's reputation, the patients one sees, the journals one reads and perhaps publishes in, and indeed one's income are all linked to one's psychotherapeutic approach. Alternatively, one is forced back to what may seem like a return to the original dilemma, an eclecticism that is merely a random selection of techniques without any real theoretical foundation.

\section{PLURALISTIC SOLUTION}

The development of cognitive maturity in the young adult depends not on the strict application of abstract, relativistic modes of reasoning, but on a new kind of concretism in which all available contradictory perspectives are preserved. A personalized perspective develops which allows a self to differentiate out of a diffuse sea of possible alternatives. In the mature psychotherapist, there is an acceptance of a variety of approaches and often the use of methods from contradictory philosophies that is more systematic than random eclectism, but has no formal theory. What is needed, then, is a formal theoretical perspective that is able to accommodate a variety of personalized perspectives.

The philosophical approach of "pluralism" is one possible solution. Nozick (11) describes "pluralism" as a delimiting strategy for modifying world views, capturing what is true in each, and making them compatible parts of one new view. Walsh and Peterson (6) have cited this philosophical perspective as the most intellectually responsible approach to resolving the conflict that now exists between the schools of psychotherapy. Chandler (7) describes the solution for the adolescent, and perhaps we can learn from this to bring the factions dividing psychotherapists together.

Although short cut remedies are sometimes sought in the quackery of cliquishness, prejudice, and syncretistic abstractions, more legitimate cures are to be found in dialectical solutions which do not sacrifice the particular to the general, but preserve both in a common embrace.

\section{REFERENCES}

1. Black D, Ascher J, Cash H, et al.: Should psychotherapy be taught to psychiatric residents? A debate. Jefferson Journal of Psychiatry 5:54-66, 1987

2. Dollard J and Miller NE: Personality and Psychotherapy. New York, McGraw-Hill, 1950

3. Meichenbaum D: Cognitive Behavior Modification. New York, Plenum Press, 1978

4. Wachtel PL: Psychoanalysis and Behavior Therapy. New York, Basic Books, 1977

5. Goldfried MR: Toward the delineation of therapeutic change principles. American Psychologist 35:991-999, 1980 
6. Walsh BW and Peterson LE: Philosophical foundations of psychological theories: The issue of synthesis. Psychotherapy 22:145-153, 1985

7. Chandler MJ: Relativism and the problem of epistemological loneliness. Human development 18:171-180, 1975

8. Sartre J: Being and Nothingness. New York, Philosophical Library, 1965

9. Skinner BF: Beyond Freedom and Dignity. New York, AA Knopf, 1971

10. Freud S: Civilization and Its Discontents. New York, Hogarth Press, 1930

11. Nozick R: Philosophical Explanations. Cambridge, MA, Harvard University Press, 1981 